\title{
Correction to: Sex Offenders of East Asian Heritage Resemble Other Canadian Sex Offenders
}

\author{
Seung C. Lee ${ }^{1}$ - R. Karl Hanson ${ }^{1,2}$. \\ Carmen L. Zabarauckas ${ }^{3,4}$
}

Published online: 2 November 2017

(C) Springer Science+Business Media B.V. 2017

\section{Correction to: Asian Criminology https://doi.org/10.1007/s11417-017-9252-y}

The original version of this article unfortunately contained an error.

The Appendix table was incorrectly formatted and entries were misaligned. The correct table is now given in this article.

The original article was corrected.

The online version of the original article can be found at https://doi.org/10.1007/s11417-017-9252-y

\section{Seung C. Lee}

seungc.lee@carleton.ca

1 Department of Psychology, Carleton University, 1125 Colonel By Drive, Ottawa, ON K1S 5B6, Canada

2 Public Safety Canada, 340 Laurier Avenue West, Ottawa, ON K1A 0P8, Canada

3 BC Corrections, 1001 Douglas Street, Victoria, BC V8W 9J7, Canada

4 Simon Fraser University, 8888 University Drive, Burnaby, BC V5A 1S6, Canada 


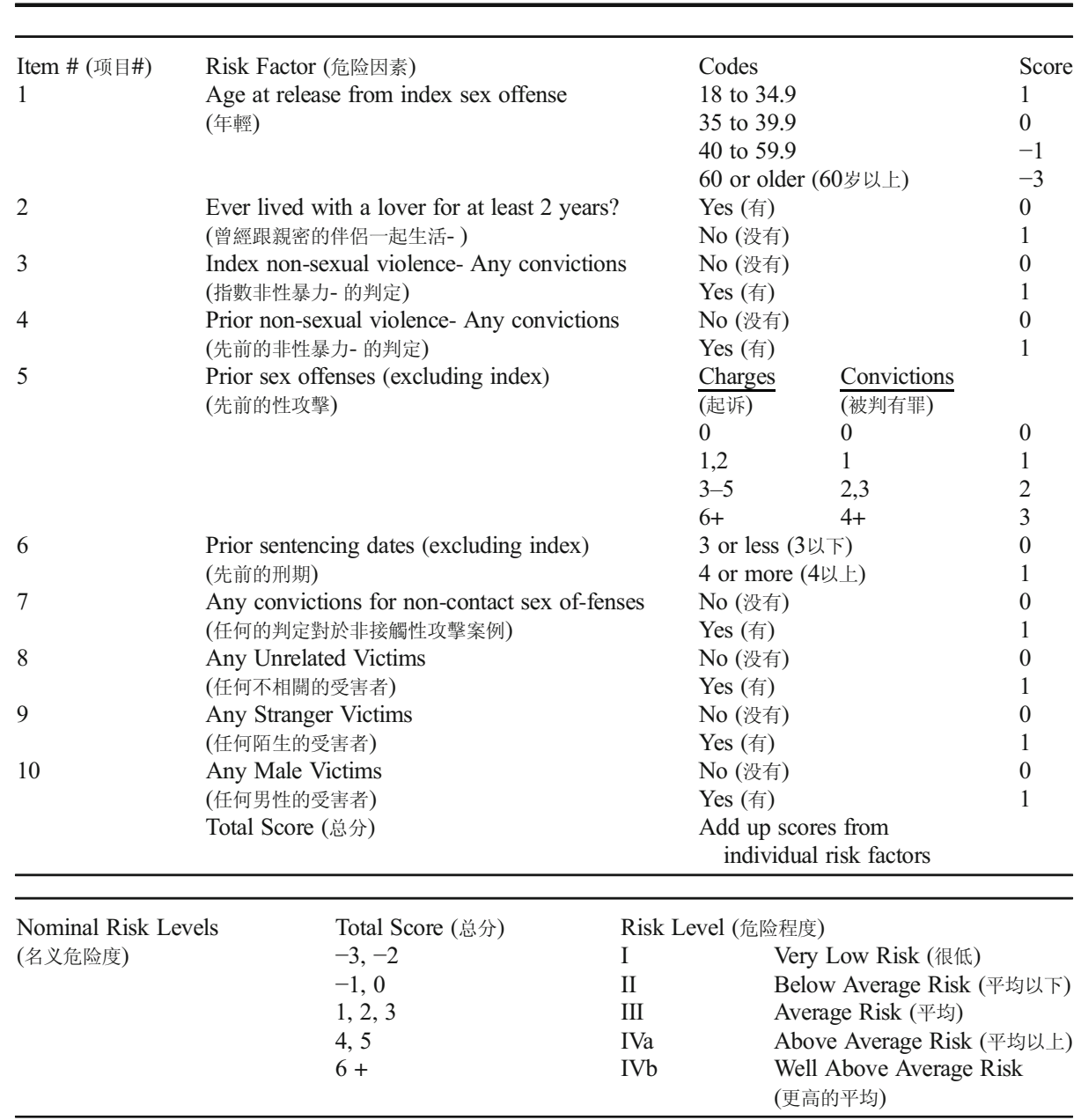

